\section{Growth Characteristics of a Small-fruit Dwarf Mutant Arising from Bud Sport Mutation in Japanese Persimmon (Diospyros kaki Thunb.)}

\author{
Hisayo Yamane', Megumi Ichiki, Ryutaro Tao, Tomoya Esumi, and \\ Keizo Yonemori \\ Graduate School of Agriculture, Kyoto University, Kyoto 606-8502, Japan \\ Takeshi Niikawa \\ Gifu Prefectural Agricultural Technology Center, Gifu 501-1152, Japan
}

Hino Motosugi

University Farm, Kyoto Prefectural University, Seika-cho, Kyoto 619-0244, Japan

Additional index words. dwarf rootstock, fruit size, sugar composition, tannin, tissue culture

Abstract. Fruit size is one of the most important traits that affect the economic value of fruit. In persimmon (Diospyros kaki Thunb.), somatic and bud-sport mutations that affect the fruit traits are frequently observed. Recently, a small-fruit mutant, 'Totsutanenashi' (TTN), was discovered in Japan as a bud-sport mutant of the leading cultivar Hiratanenashi (HTN). In this study, we investigated the morphological and physiological characteristics of TTN and HTN focusing on the tree architecture, fruit size, and the fruit flesh chemical composition. The objectives of the study were to evaluate the potential horticultural use of TTN and to characterize the differences between HTN and TTN. Both TTN and HTN are nonaploid plants, indicating that a difference in ploidy is not the cause of the small-fruit mutation. The vegetative growth of trees and tissue-cultured shoots of TTN was more compact than that of HTN. The floral organs of TTN appeared similar to those of HTN before flowering, but the TTN flowers opened earlier, resulting in smaller ovaries than in HTN flowers. The fruit size of TTN was consistently lower than that of HTN at all fruit developmental stages. TTN fruit had a higher sugar content and a higher proportion of sucrose to total sugars than HTN fruit. TTN fruits contained lower levels of secondary metabolites such as soluble tannins and ascorbate than HTN fruits. These results suggest that the fruit size mutation also affects the fruit biochemistry, leading to alterations in the fruit flesh composition. TTN may be a valuable genetic resource because compact trees require less labor and maintenance, and small, sweeter fruits may meet the various needs of consumers. The use of TTN in studies of the genetic control of fruit size is also discussed.

Fruit size is one of the most important traits that affect the economic value of fruit. Although fruit size is controlled by both environmental and genetic factors, the latter have the greatest impact, because small genetic changes can dramatically affect the fruit size. Thus, improvements in fruit size are usually achieved by the introduction of new traits. However, little is known about the key genetic factors that regulate fruit size in most fruit tree species. Our goal is to isolate these factors that control fruit size and to elucidate the physiological changes caused by changes in the fruit size.

The weight of persimmon (Diospyros kaki Thunb.) fruit ranges from less than $60 \mathrm{~g}$ to more than $300 \mathrm{~g}$ depending on the cultivar.

Received for publication 18 Apr. 2008. Accepted for publication 4 July 2008

We thank Mr. M. Kondo and Dr. H. Kunitake, Miyazaki University for providing us the plant materials.

${ }^{1}$ To whom reprint requests should be addressed; e-mail hyamane@kais.kyoto-u.ac.jp
Somatic or bud-sport mutations that affect fruit size are common (Yonemori et al., 2000). Recently, a small-fruit mutant, Totsutanenashi (TTN), which originated from the leading cultivar in Japan, Hiratanenashi (HTN), was discovered in Masaharu Kondo's orchard in Sado, Niigata Prefecture, Japan. We have obtained the scions of TTN and propagated by grafting for several years. Our preliminary simple sequence repeat (SSR) data using the published SSR primer sets for Japanese persimmon (Soriano et al., 2006) suggested the genetic identity between TTN and HTN. In this report, we determined the ploidy level of the two cultivars. Then, to investigate the growth characteristics of TTN, we compared the morphological characteristics of vegetative and reproductive organs of TTN and HTN plants and the physiological properties of their fruit.

\section{Materials and Methods}

Plant materials and characterization of vegetative growth. Six trees of each of the two Japanese persimmon cultivars, HTN and its bud-sport mutant, TTN, both of which were grafted onto seedling rootstocks, were used. All trees were grafted at the same time and grown in 60-L containers for 3 years at the Kyoto University experimental farm, Kyoto, Japan $\left(34^{\circ} \mathrm{N}, 135^{\circ} \mathrm{E}\right)$. In July 2005 , the shoot and internode lengths were measured. Three of six pot-grown trees were then planted in an orchard at the Kyoto University experimental farm in Mar. 2006 and cultivated using commercial management methods, including a normal pruning system. In Oct. 2007, the shoot and internode lengths of the five uppermost shoots from the longest shoots on each plant were investigated.

Axillary buds were collected in 2005 from the annual shoots of pot-grown trees $\approx 20 \mathrm{~d}$ after bud burst and sterilized as described (Sugiura et al., 1986). The explants were placed in the initial shoot culture medium and subcultured at $\approx 3$-week intervals. Murashige and Skoog medium (MS) containing $5 \mu \mathrm{M}$ zeatin was used as the basal medium. After 2 years of repeated subculturing, the shoots were transferred to MS containing 5 or $10 \mu \mathrm{M}$ zeatin. After 3 weeks of culture, the average number of shoots per explant and the average shoot length were investigated using 10 explant replicates from the two cultivars.

In 2005 and 2006 growing season, equal fruit load (two fruits per current shoot) was achieved in three pot-grown trees of two cultivars by hand thinning after June drop. Fruits were harvested periodically during their development and maturation stages from these trees and used for the analysis of tannin contents. Three fruits were used for this analysis. A fruit skin-color index that indicates similar developmental stages of the fruits has been developed for HTN (National Agricultural Research Station, Tsukuba, Japan). Mature fruits with values of 6.5 and 8.0 according to the HTN color chart index were harvested in 2006 and analyzed for their sugar content, and fruits with values of 5.5 and 7.5 were used for analysis of ascorbate content. Triplicates of three fruits were analyzed for each measurement.

Determination of ploidy levels. Calli were induced from leaf primordia of TTN, HTN, and the reference cultivar, Jiro $(6 \times)$ in callusinduction medium (half nitrogen source of MS with $10 \mu \mathrm{M}$ zeatin and $1 \mu \mathrm{M}$ indoleacetic acid) (Tao et al., 1988). The ploidy levels of TTN and HTN calli were determined using a flow cytometer (FACSCalibur; BectonDickinson, Franklin Lakes, NJ) as described by Sugiura et al. (2000). To prepare samples for flow cytometry, small tissue samples $(\approx 5$ $\mathrm{mg}$ ) were immersed in nuclei extraction buffer (Partec, Munster, Germany) and macerated with a razor blade to release nuclei. The suspension was incubated for $5 \mathrm{~min}$ and then passed through $20-\mu \mathrm{m}$ nylon mesh to remove debris. The nuclei in the filtrate were stained with propidium iodide and subjected to flow cytometric analysis.

Characterization of reproductive development. Flower buds were collected on 25 Apr. and 2 May 2006 from pot-grown 

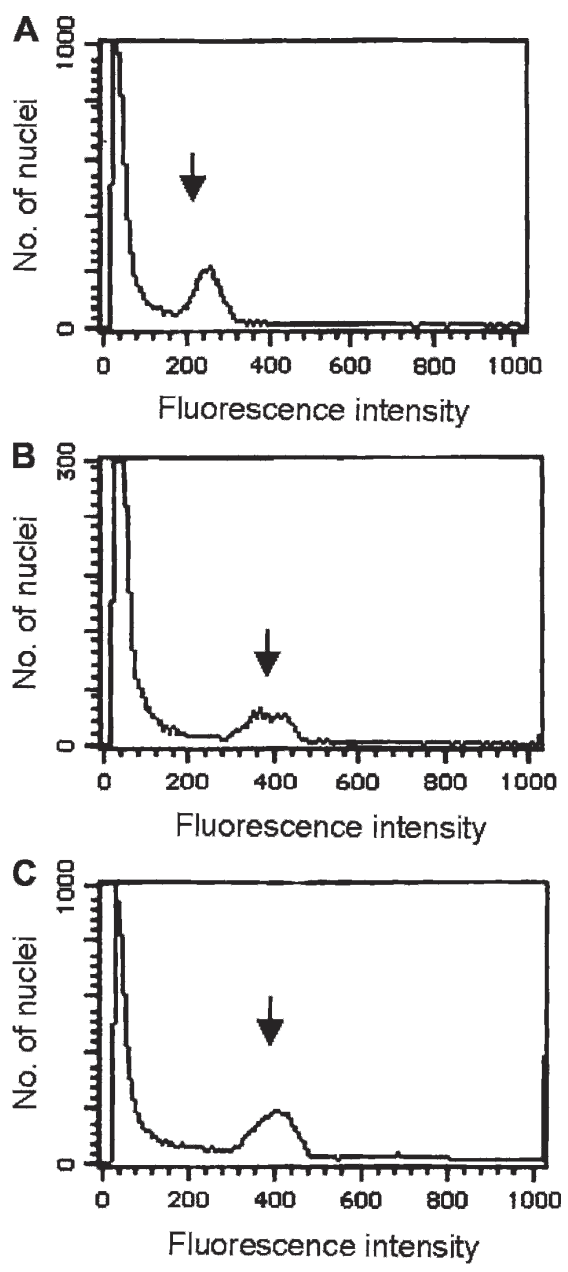

Fig. 1. Relative fluorescence intensity of TTN and HTN obtained by flow cytometry. As reference, relative fluorescence intensity of 'Jiro' $(6 \times)$ was also measured. (A) 'Jiro' callus (6×); (B) TTN callus $(9 \times)$; (C) HTN callus $(9 \times)$. Arrows indicate the peak of the relative nuclear DNA content. TTN = 'Totsutanenashi'; HTN = 'Hiratanenashi',

Table 1. Growth properties of vegetative organs of pot-grown (3-year-old) and field-grown (5-year-old) HTN and TTN trees.

\begin{tabular}{|c|c|c|c|c|c|c|}
\hline & \multicolumn{2}{|c|}{ Pot-grown trees } & \multicolumn{4}{|c|}{ Field-grown trees } \\
\hline & $\begin{array}{c}\text { Percentage } \\
\text { of long stem } \\
(\%)^{z}\end{array}$ & $\begin{array}{l}\text { Internode length } \\
\text { of long stem } \\
(\mathrm{cm})\end{array}$ & $\begin{array}{l}\text { Shoot } \\
\text { length } \\
(\mathrm{cm})\end{array}$ & $\begin{array}{l}\text { Node no. } \\
\text { (per } \\
\text { shoot) }\end{array}$ & $\begin{array}{l}\text { Node no. } \\
\text { (per } 1 \mathrm{~cm} \\
\text { of shoot) }\end{array}$ & $\begin{array}{l}\text { Internode } \\
\text { length } \\
(\mathrm{cm})\end{array}$ \\
\hline TTN & 20.9 & $2.5 \pm 0.2^{y}$ & $111.5 \pm 20.6$ & $47.7 \pm 14.0$ & $0.42 \pm 0.06$ & $2.0 \pm 0.3$ \\
\hline HTN & 38 & $3.2 \pm 0.2$ & $77.1 \pm 35.8$ & $19.4 \pm 6.9$ & $0.25 \pm 0.08$ & $3.8 \pm 0.8$ \\
\hline $\begin{array}{l}\text { Statistical } \\
\quad \text { significance }\end{array}$ & * & * & * & ** & ** & $* *$ \\
\hline
\end{tabular}

${ }^{2}$ Branches longer than the average length of HTN branches $(14.3 \mathrm{~cm})$ were categorized as long stem. ${ }^{\mathrm{y}}$ Mean $\pm \mathrm{SD}$.

*, ** Significant at $P<0.05$ and 0.01 by $t$ test, respectively.

HTN $=$ 'Hiratanenashi'; TTN $=$ 'Totsutanenashi'.

Table 2. Growth properties of vegetative organs of micropropagated HTN and TTN shoots in flask ${ }^{z}$.

\begin{tabular}{lccccc}
\hline & \multicolumn{2}{c}{ Zeatin $5 \mu \mathrm{M}$} & & \multicolumn{2}{c}{ Zeatin 10 $\mu \mathrm{M}$} \\
\cline { 2 - 3 } \cline { 6 - 6 } & $\begin{array}{c}\text { Number } \\
\text { of shoots }\end{array}$ & $\begin{array}{c}\text { Shoot length } \\
(\mathrm{mm})\end{array}$ & & $\begin{array}{c}\text { Number of } \\
\text { shoots }\end{array}$ & $\begin{array}{c}\text { Shoot length } \\
(\mathrm{mm})\end{array}$ \\
\hline TTN & $3.08 \pm 0.95^{\mathrm{y}}$ & $9.65 \pm 5.88$ & & $3.55 \pm 0.88$ & $9.52 \pm 3.84$ \\
HTN & $200 \pm 0.92$ & $16.20 \pm 9.90$ & & $1.75 \pm 0.46$ & $17.55 \pm 9.56$ \\
Statistical significance & $*$ & $*$ & & $* *$ & $*$ \\
\hline
\end{tabular}

${ }^{\mathrm{z}}$ Murashige and Skoog medium containing either 5 or $10 \mu \mathrm{M}$ zeatin was used for shoot culture.

${ }^{\mathrm{y}}$ Mean $\pm \mathrm{SD}$.

${ }^{*},{ }^{* *}$ Significant at $P<0.05$ and 0.01 by $t$ test, respectively.

$\mathrm{HTN}=$ 'Hiratanenashi'; TTN $=$ 'Totsutanenashi'. methanol and centrifuged. Folin-Ciocalteau reagent (Wako, Tokyo, Japan) was added to the supernatant, and the soluble tannin concentration was analyzed with an ultraviolet/visible spectrophotometer $(725 \mathrm{~nm})$ (Shimadzu; ultraviolet-1600). The tannin concentration was expressed as $(+)$-catechin equivalents.

For ascorbate (vitamin C) analysis, samples were homogenized with 5\% meta-phosphoric acid and centrifuged. Ascorbate and dehydroascorbate concentrations in the supernatant were measured using a reverse-phase high-performance liquid chromatographyultraviolet/visible system fitted with an ODS-3 column (Nihon Bunko, Tokyo, Japan) as described by Niikawa et al. (2007). Measurements were made in triplicate on three replicate fruits.

\section{Results and Discussion}

Ploidy level of the small-fruit bud-sport mutant 'Totsutanenashi'. HTN was reported to be nonaploid (Zhuang et al., 1990), although most commercial persimmon cultivars grown in Japan are hexaploid $(2 \mathrm{n}=6 \mathrm{x}, \mathrm{x}=15)$ (Namikawa and Higashi, 1928). HTN has characteristics commonly observed in triploids such as vigorous growth, lack of seeds, and enlarged cell size, which may account for its high yield and fruit quality. These characteristics make HTN a leading cultivar accounting for nearly $35 \%$ of persimmon production in Japan. Its small-fruited bud-sport mutant, TTN, was recently discovered in Sado, Niigata Prefecture. The ploidy levels of both cultivars were compared by flow cytometric analysis. The peaks indicating relative nuclear DNA content were identical in calli of TTN and HTN (Fig. 1), indicating that TTN is also nonaploid. This suggests that a ploidy mutation is not responsible for the morphological differences between TTN and HTN.

Dwarf growth characteristics of 'Totsutanenashi'. TTN had a larger number of flowers and fruits per shoot than HTN (data not shown), suggesting that it has more branches. The vegetative growth characteristics of TTN and HTN were investigated to evaluate the tree architecture of each by comparing the branch and internode lengths of trees grown in containers or in an orchard. Branches longer or shorter than the average length of HTN branches $(14.3 \mathrm{~cm})$ were categorized as long or short stems, respectively. In pot-grown trees, the proportion of long stems was significantly lower in TTN than HTN (Table 1). The mean internode length of TTN was less than that of HTN, and the number of nodes was significantly higher in TTN shoots in field-grown trees (Table 1). The tree architecture of TTN is therefore more compact and dwarf than that of HTN. This result was further supported by data from micropropagated plants, which confirmed the dwarf growth habit of TTN. The number of shoots was significantly higher in TTN and shoot length was significantly lower in TTN than HTN in MS containing either 5 or $10 \mu \mathrm{M}$ zeatin (Table 2). Therefore, TTN 
showed dwarf growth characteristics in all growth environments examined in this study. A dwarf phenotype in fruit trees is favored by farmers because of their ease of management (Faust and Zagaja, 1984). Indeed, dwarfing rootstocks have been bred and introduced into many fruit tree species such as apple (Koike and Tsukahara, 1993), Citrus (Phillips and Castle, 1977), and sweet cherry (Giorgio and Standardi, 1993). At present, no practical dwarfing rootstock or dwarfing culture is available for Japanese persimmon, and there are efforts to create dwarfing rootstocks (Koshita et al., 2007). The dwarf trait in TTN could be used as a valuable material for breeding dwarf Japanese persimmon cultivars.

Growth characteristics of 'Totsutanenashi' reproductive organs. Floral organ development in flower buds of TTN and HTN was examined on 25 Apr. and 2 May 2006. The average flowering date was 10 May 2006 in TTN and 20 May 2006 in HTN. On 25 Apr., initiation of stamens (later aborted because both TTN and HTN only bear female flowers) and carpels were observed in both TTN and HTN followed by ovule formation and the completion of floral organ development on 2 May, suggesting that floral organs develop similarly in TTN and HTN (Fig. 2B). Considering that TTN flowers opened $\approx 10 \mathrm{~d}$ earlier than HTN flowers, it appears that TTN flowers open before their floral organs are fully expanded (Fig. 2B-C).

In Japanese persimmon, fruit growth and development is typically divided into three phases: 1) maximal growth corresponding to the first sigmoidal growth phase; 2) cessation of growth corresponding to a lag between the first and second sigmoidal phases; and 3) maximal growth corresponding to the second sigmoidal phase. Although changes in the diameters of HTN fruit followed a doublesigmoidal curve during the fruit growth and development period, no similar rapid growth was observed in TTN fruits (Fig. 3). At the time of commercial harvesting, the average diameter of TTN fruit was less than one-third that of HTN fruit (Figs. 2A, D).

Flesh composition in 'Totsutanenashi' and 'Hiratanenashi' fruits. The major soluble sugars in persimmon (glucose, fructose, and sucrose) were examined. The sum of these three sugars is referred to as the total sugar content. During both developmental stages examined, the sucrose content was higher in TTN than HTN, resulting in a higher total sugar content in TTN fruit (Table 3). Zheng and Sugiura (1990) found that the amount of sucrose as a percentage of the total sugars was lower in HTN fruit (41\% when the fruit reached 8.0 on the color chart) than in other persimmon varieties. TTN fruit, however, contained more sucrose $(49 \%$ when the fruit reached 8.0 on the color chart) and had a higher total sugar content (more than $20 \%$ of fresh weight) than HTN fruit. Hence, the higher amount of sugar in TTN fruit is an advantageous agronomic characteristic. It is thought that the lower level of sucrose in HTN fruit than TTN is caused by the higher invertase activity in HTN fruits, because the leaf photosynthate is translocated to the sink organs (fruits) as sucrose, which is stored in fruit or converted to monosaccharides such as glucose and fructose by mainly invertase and other metabolic enzymes in persimmon. Thus, the higher percentage of sucrose in TTN may be related to the lower invertase activity in the fruits. However, because lower invertase activity often causes lower amounts of fructose and glucose but appeared not occur in TTN fruits, further studies are required to examine this idea.

We also determined the soluble tannin and ascorbate contents, because relatively

A

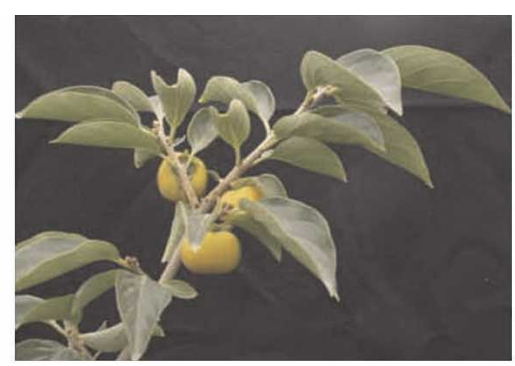

TTN

B

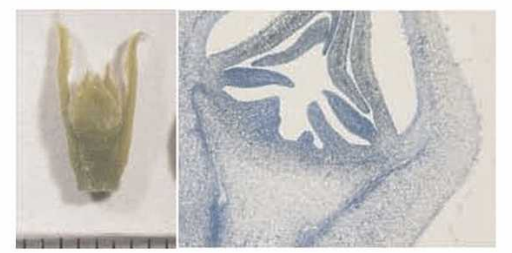

TTN (April 25, 2006)

( 2 weeks before flowering)

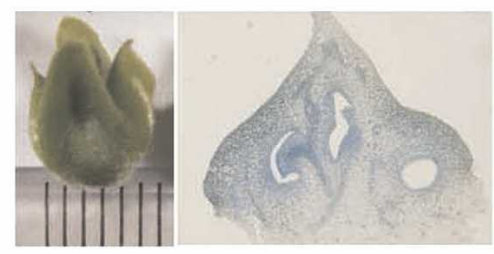

TTN (May 2, 2006)

(1 week before flowering)

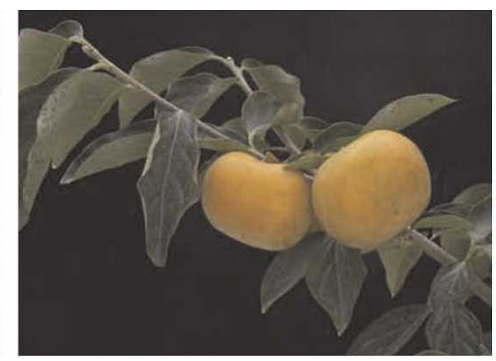

HTN

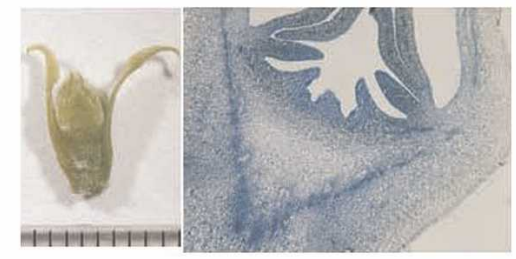

HTN (April 25, 2006)

( 3 weeks before flowering)

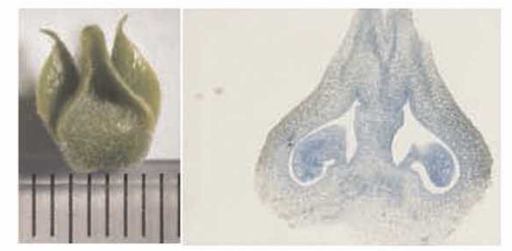

HTN (May 2, 2006)

( 2 weeks before flowering)

C
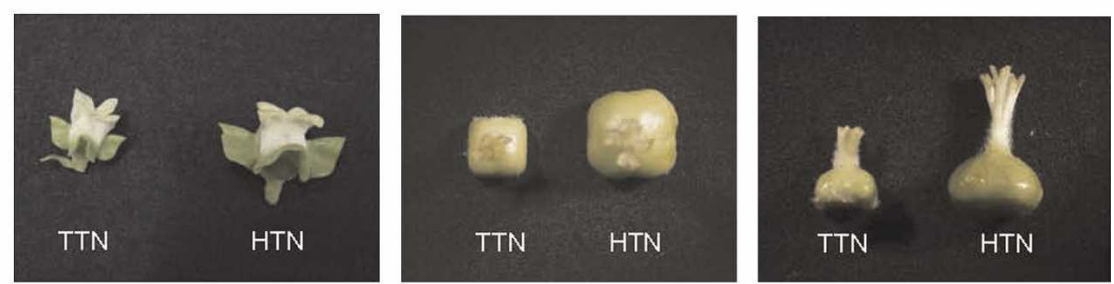

D
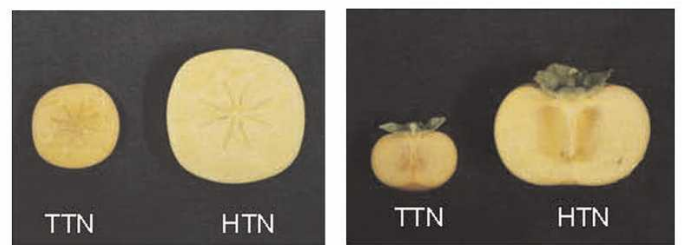

Fig. 2. Photographs of reproductive organs of TTN and HTN. (A) Fruits on the pot-grown trees. (B) Flower bud and floral organ development observed by microscope. In each section, the left photograph shows the whole flower buds, whereas right photograph shows toluidine blue-stained flower primordia in flower buds. (C) Flowers and ovaries at flowering. Left photograph shows flowers, whereas center and right photographs show top and side of ovaries, respectively, dissected from flowers at flowering. (D) Fruits at commercial harvest period. Left and right photographs show cross and longitudinal section of fruits, respectively. TTN = 'Totsutanenashi'; HTN = 'Hiratanenashi'. 


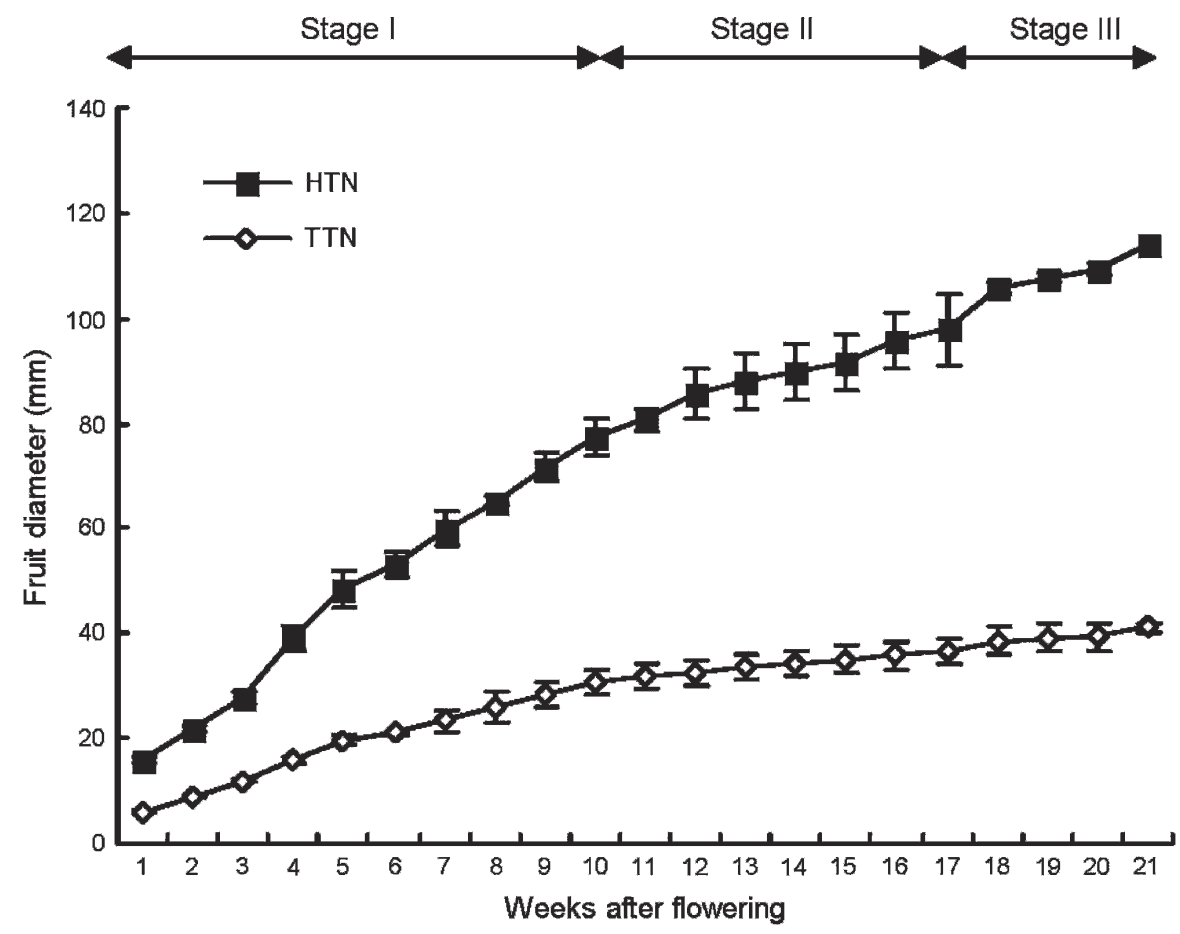

Fig. 3. Fruit diameter of 'Totsutanenashi' (TTN) and 'Hiratanenashi' (HTN) during fruit growth and development.

was lower than that in HTN fruits throughout fruit development (Fig. 4), suggesting that tannin biosynthesis is lower in TTN fruits than in HTN fruits. In both developmental stages, the ascorbate and dehydroascorbate contents in TTN fruits were lower than in HTN fruits (Table 3). The lower amounts of soluble tannins and ascorbate suggest that the secondary metabolic activity of TTN is lower than that of HTN. The higher sucrose content as a percentage of total sugars, probably caused by the lower invertase activity in TTN, also supports this suggestion. Similar results were also found in a grape mutant. Fernandez et al. (2006) reported that the fleshless berry mutant of grape, which has a low pericarp weight, contains fewer phenolic compounds and a higher proportion of sucrose in relation to total sugars during berry development. This finding suggested that a mutation in the fruit size affects the bio- chemical properties of the fruit. On the other hand, however, Klann et al. (1996) reported that the changes in sugar composition in tomato fruit contribute to alterations in fruit size. This finding suggested that smaller fruit size could be caused by alterations of biochemical properties of the fruits. In this study, dwarf growth character, reduced fruit size, and alterations of fruit composition were observed in TTN. Although we could not rule out the possibility that its reduced fruit size is caused by the alterations of fruit biochemical compounds, the changes in both vegetative and reproductive organs of TTN suggested that the mutation affecting the whole plant growth could contribute to the alterations in fruit biochemical properties. Further biochemical studies would be required for characterization of the mutation in TTN.

Many bud-sport mutants have been identified in HTN (Yonemori et al., 2000). For example, 'Otanenashi' is a bud-sport mutant bearing bigger fruits (Hamada et al., 2004). 'Tonewase', an early-maturing mutant derived from HTN, is widely cultivated in Wakayama Prefecture, one of the main persimmon-producing areas in Japan. The increased frequency of transpositions and other chromosomal rearrangements is thought to be associated with recent polyploidy (Zhao et al., 1998). Thus, polyploidy in Japanese persimmons, in which hexaploid or nonaploid plants are common, would enhance the occurrence of mutations, resulting in the emergence of many valuable bud sports such as TTN. Little is known about the genetic control of fruit size in Japanese persimmons, despite the diverse fruit sizes of the cultivars. Hence, TTN may prove useful for studying genes that control fruit size in Japanese persimmon as recently elucidated for the fleshless berry grape mutant (Fernandez et al., 2007). To date, because relatively small genetic changes might be associated with arising bud-sport mutation from original plant, bud-sport mutants were successfully used for the discovery of the genes related to important agronomic traits in fruit tree species such as skin color in grape (Kobayashi et al., 2004) and self-incompatibility in Rosaceae (Sassa et al., 1997; Tao et al., 1997). In addition, bud-sport deletion mutant was successfully used for complementation experiment by introducing intact functional genes, resulting in the alteration of phenotype (Kobayashi et al., 2004). Further genomic studies by searching for the genomic differences despite the nearly same genetic background between TTN and HTN would lead to finding the factors causing the morphological and physiological differences between TTN and HTN.

This study has clearly demonstrated that a ploidy mutation is not associated with the morphology of TTN. The growth characteristics of TTN, which forms compact trees with small fruits, may provide a valuable genetic resource that requires a less labor-intensive cultural system while providing small fruit to meet the various needs of consumers. In addition, the higher sugar content of TTN fruits is an attractive commercial characteristic. We are currently undertaking an analysis of the basis of the fruit size differences between TTN and

Table 3. Soluble sugar and ascorbates contents in mature fruits of HTN and TTN 2 .

\begin{tabular}{|c|c|c|c|c|c|c|c|c|}
\hline & \multicolumn{4}{|c|}{ Soluble sugar contents $\left(6.5^{y}\right)$} & \multicolumn{4}{|c|}{ Soluble sugar contents $\left(8.0^{\mathrm{y}}\right)$} \\
\hline & $\begin{array}{c}\text { Fructose } \\
(\%)\end{array}$ & $\begin{array}{c}\text { Glucose } \\
(\%)\end{array}$ & $\begin{array}{c}\text { Sucrose } \\
(\%)\end{array}$ & $\begin{array}{c}\text { Total sugar } \\
(\%)\end{array}$ & $\begin{array}{c}\text { Fructose } \\
(\%)\end{array}$ & $\begin{array}{c}\text { Glucose } \\
(\%)\end{array}$ & $\begin{array}{c}\text { Sucrose } \\
(\%)\end{array}$ & $\begin{array}{c}\text { Total sugar } \\
(\%)\end{array}$ \\
\hline$\overline{\mathrm{TTN}}$ & $2.93 \pm 0.90^{x}$ & $4.57 \pm 0.21$ & $9.33 \pm 1.01$ & $16.83 \pm 0.51$ & $4.90 \pm 0.71$ & $5.78 \pm 0.32$ & $9.54 \pm 0.68$ & $20.21 \pm 0.95$ \\
\hline
\end{tabular}

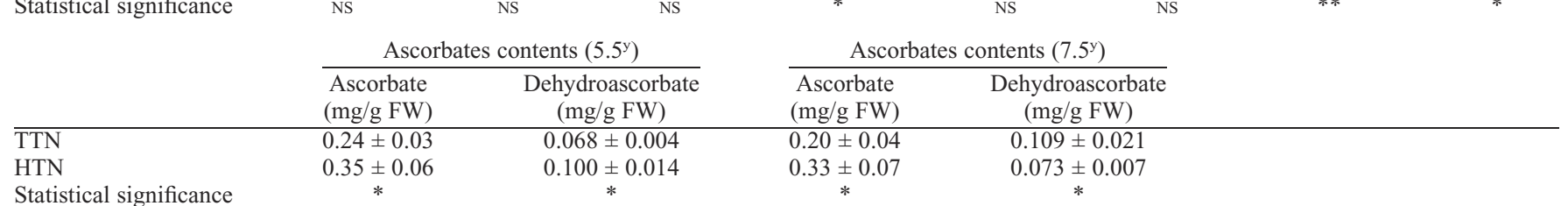

${ }^{\mathrm{z}}$ Fruit maturation stages were designated by color chart index.

${ }^{\mathrm{y}}$ Color chart index values developed for HTN (National Agricultural Research Station, Japan).

${ }^{\mathrm{x}}$ Mean $\pm \mathrm{SD}$.

${ }_{\mathrm{Ns},}^{*},{ }^{* *}$ Nonsignificant or significant at $P<0.05$ and 0.01 by $t$ test, respectively.

$\mathrm{HTN}=$ 'Hiratanenashi'; TTN = 'Totsutanenashi'; FW = fresh weight. 


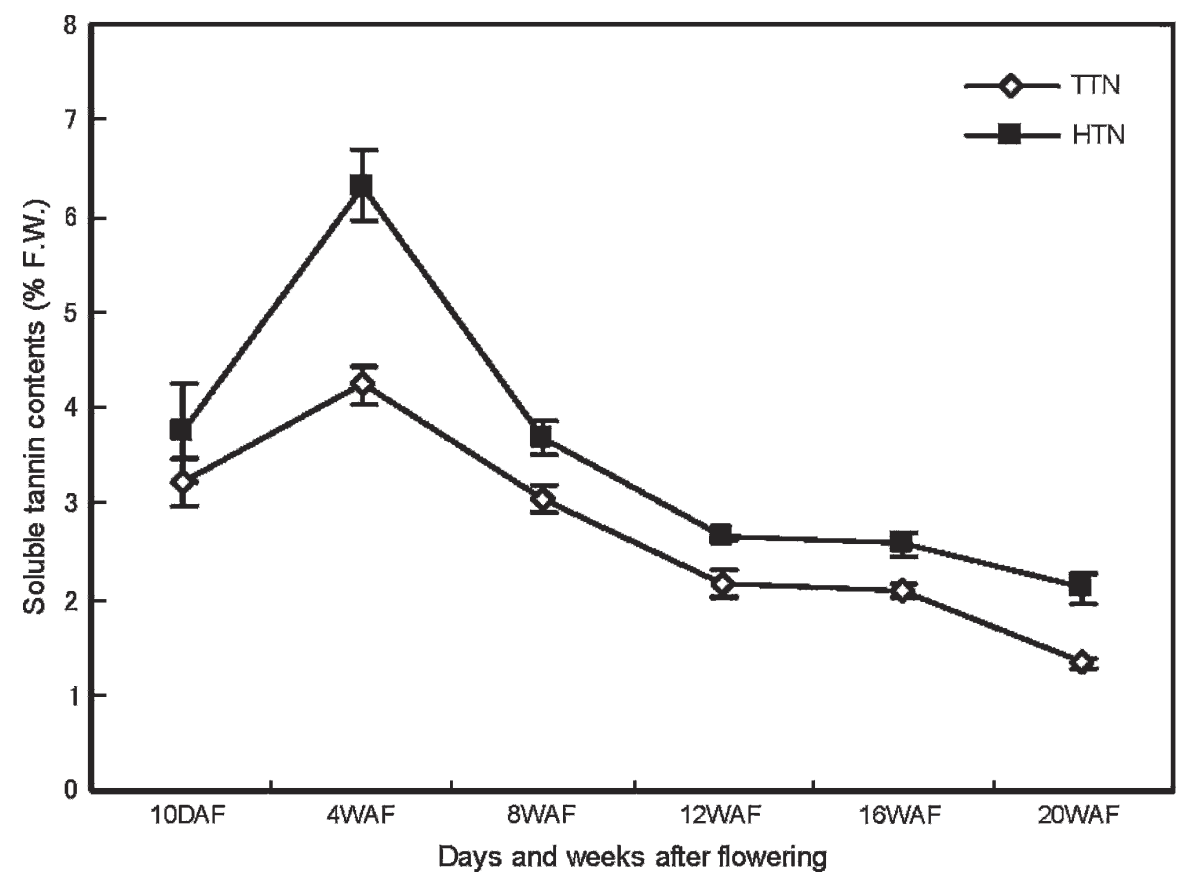

Fig. 4. Soluble tannin contents in 'Totsutanenashi' (TTN) and 'Hiratanenashi' (HTN) fruits during fruit growth and development.

HTN with an ultimate goal of identifying the genetic factors that regulate fruit size.

\section{Literature Cited}

Faust, M. and S.W. Zagaja. 1984. Prospects for developing low vigor fruit tree cultivars. Acta Hort. 146:21-27.

Fernandez, L., C. Romieu, A. Moing, A. Bouquet, M. Maucourt, M.R. Thomas, and L. Torregrosa. 2006. The grapevine fleshless berry mutation. A unique genotype to investigate differences between fleshy and nonfleshy fruit. Plant Physiol. 140:537-547.

Fernandez, L., L. Torregrosa, N. Terrier, L. Sreekantan, J. Grimplet, C. Davies, M.R. Thomas, C. Romieu, and A. Ageorges. 2007. Identification of genes associated with flesh morphogenesis during grapevine fruit development. Plant Mol. Biol. 63:307-323.

Gao, M., R. Tao, K. Miura, A.M. Dandekar, and A. Sugiura. 2001. Transformation of Japanese persimmon (Diospyros kaki Thunb.) with apple cDNA encoding NADP-dependent sorbitol-6phosphate dehydrogenase. Plant Sci. 160:837845.

Giorgio, V. and A. Standardi. 1993. Growth and Production of two sweet cherry cultivars grafted on 60 ecotypes of Prunus mahaleb. Acta Hort. 410:471-476.

Hamada, K., K. Hasegawa, A. Kitajima, and T. Ogata. 2004. Relationship of fruit size and mesocarp cell size and cell number in 'Otane- nashi', 'Hiratanenashi' and 'Saijo'. J. Jpn. Soc. Hort. Sci. 73:(Suppl. 2):344 (abstr. in Japanese). Hirano, K., K. Yonemori, and A. Sugiura. 1995. Involvement of sugar metabolism in persimmon growth inhibition by calyx lobe removal. J. Amer. Soc. Hort. Sci. 120:75-77.

Ikegami, A., K. Yonemori, A. Sugiura, A. Sato, and M. Yamada. 2004. Segregation of astringency in $\mathrm{F} 1$ progenies derived from crosses between pollination-constant, nonastringent persimmon cultivars. HortScience 39:371-374.

Klann, E.M., B. Hall, and A.B. Bennett. 1996. Antisense acid invertase (TIV1) gene alters soluble sugar composition and size in transgenic tomato fruit. Plant Physiol. 112:13211330.

Kobayashi, S., N. Goto-Yamamoto, and H. Hirochika. 2004. Retrotransposon-induced mutations in grape skin color. Science 304:982.

Koike, H. and K. Tsukahara. 1993. Studies on root system and growth of 'Fuji' apple trees on dwarfing interstock and rootstocks. J. Jpn. Soc. Hort. Sci. 62:49-54.

Koshita, Y., K. Morinaga, Y. Tsuchida, T. Asakura, H. Yakushiji, and A. Azuma. 2007. Selection of interstocks for dwarfing Japanese persimmon (Diospyros kaki Thunb.) trees. J. Jpn. Soc. Hort. Sci. 76:288-293.

Namikawa, I. and M. Higashi. 1928. On the chromosomes in Diospyros kaki L. F. and Diospyros lotus L. Bot. Magazine 42:436438.

Niikawa, T., T. Ozeki, N. Miyake, and T. Kurata. 2007. Effect of variety, maturation and culti- vation method on vitamin $\mathrm{C}$ contents in Japanese persimmon. Hort. Res. 6:(Suppl. 2):114. [in Japanese].

Oshida, M., K. Yonemori, and A. Sugiura. 1996. On the nature of coagulated tannins in astringent-type persimmon fruit after artificial treatment of astringency removal. Postharvest Biol. Tech. 8:317-327.

Phillips, R.L. and W.S. Castle. 1977. Evaluation of the twelve rootstocks for dwarfing citrus. J. Amer. Soc. Hort. Sci. 102:526-528.

Sassa, H., H. Hirano, T. Nishino, and T. Koba. 1997. Style-specific self-compatible mutation caused by deletion of the S-RNase gene in Japanese pear (Pyrus serotina). Plant J. 12: 223-227.

Soriano, J.M., S. Pecchioli, C. Romero, S. Vilanova, G. Llacer, E. Giordani, and M.L. Badenes. 2006. Development of microsatellite markers in polyploidy persimmon (Diospyros kaki Thunb.) from an enriched genomic library. Mol. Ecol. Notes 6:368-370.

Sugiura, A., T. Ohkuma, Y.A. Choi, R. Tao, and M Tamura. 2000. Production of nonaploid $(2 \mathrm{n}=9 \mathrm{x})$ Japanese persimmons (Diospyros kaki) by pollination with unreduced $(2 \mathrm{n}=6 \mathrm{x})$ pollen and embryo rescue culture. J. Amer. Soc. Hort. Sci. 125:609-614.

Sugiura, A., R. Tao, H. Murayama, and T. Tomana. 1986. In vitro propagation of Japanese persimmon. HortScience 21:1205-1207.

Tao, R., H. Murayama, K. Moriguchi, and A. Sugiura. 1988. Plant-regeneration from calluscultures derived from primordial leaves of adult Japanese persimmon. HortScience 23:1055-1056.

Tao, R., H. Yamane, H. Sassa, H. Mori, T.M. Gradziel, A.M. Dandekar, and K. Yonemori. 1997. Identification of stylar RNases associated with gametophytic self-incompatibility in almond (Prunus dulcis). Plant Cell Physiol. 38:304-311.

Yonemori, K., J. Matsushima, and A. Sugiura. 1983. Differences in tannins of non-astringent and astringent type fruits of Japanese persimmon (Diospyros kaki Thunb.). J. Jpn. Soc. Hort. Sci. 52:135-144.

Yonemori, K., A. Sugiura, and M. Yamada. 2000. Persimmon genetics and breeding, p. 191225. In: Janick, J. (ed.). Plant breeding reviews 19. John Wiley \& Sons, Inc., New York, NY.

Zhao, X., Y. Si, R.E. Hanson, C.F. Crane, H.J. Price, D.M. Stelly, J.F. Wendel, and A.H. Paterson. 1998. Dispersed repetitive DNA has spread to new genomes since polyploidy formation in cotton. Genome Res. 8:479492.

Zheng, G.H. and A. Sugiura. 1990. Changes in sugar composition in relation to invertase activity in the growth and ripening of persimmon (Diospyros kaki) fruits. J. Jpn. Soc. Hort. Sci. 59:281-287.

Zhuang, D., A. Kitajima, M. Ishida, and Y. Sobajima. 1990. Chromosome number of Diospyros kaki cultivars. J. Jpn. Soc. Hort. Sci. 59:289-297. [in Japanese with English summary]. 